\title{
Treatment of pulmonary hypertension with the continuous infusion of a prostacyclin analogue, iloprost
}

\author{
T W Higenbottam, A Y Butt, A T Dinh-Xaun, M Takao, G Cremona, S Akamine
}

\begin{abstract}
Objective-To compare prostacyclin with an analogue, iloprost, in treatment of severe pulmonary hypertension.

Patients-Eight patients with severe pulmonary hypertension: primary in five, thromboembolic pulmonary hypertension in three.

Methods-All patients underwent right heart catheterisation. Mean (SEM) right atrial pressure was $9.9(2.2) \mathrm{mm} \mathrm{Hg}$, mean pulmonary artery pressure 67.4 (3.0) $\mathrm{mm} \mathrm{Hg}$, cardiac index $1.75(0.13)$ $1 / \mathrm{min} / \mathrm{m}^{2}$ and $\mathrm{mixed}$ venous oxygen saturation 59.1(3.1)\%. Continuous intravenous epoprostenol (prostacyclin, PGI ) or iloprost was given for phase I (three to six weeks); the patients were then crossed over to receive the alternate drug in an equivalent phase II.
\end{abstract}

Main outcome measures-Exercise tolerance was measured at baseline and at the end of phase I and II with a 12 minute walk; distance covered, rest period, percentage drop in arterial oxygen saturation $\left(\Delta \mathrm{Sao}_{2} \%\right)$ and percentage rise in heart rate $(\Delta \mathbf{H R} \%)$.

Results-Walking distance covered rose from (mean (SEM)) $407.5(73)$ to 591 (46) $m$ with PGI $(p=0.004)$ and to $602.5(60) \mathrm{m}$ while on iloprost $(\mathrm{p}=0.008)$. Rest period decreased from 192 (73) seconds at baseline to 16 (16) seconds with PGI $_{2}(\mathrm{p}=0.01)$ and to $58(34)$ seconds with iloprost $(p=0.008) . \Delta H R \%$ was $37.5(6) \%$ at baseline, 35(3)\% on PGI ${ }_{2}$, and $24(6) \%$ on iloprost $(p=0.04)$.

Conclusions-Both intravenous $\mathbf{P G I}_{2}$ and iloprost caused significant improvement in exercise tolerance. Iloprost offers an alternative to $\mathbf{P G I}_{2}$ treatment of severe pulmonary hypertension.

(Heart 1998;79:175-179)

Keywords: prostacyclin; vasodilatation; iloprost; pulmonary hypertension

Primary pulmonary hypertension is a serious disease with a fatal outcome in a majority of patients. ${ }^{1-3}$ Calcium channel blockers ${ }^{45}$ together with anticoagulants ${ }^{1}$ have been used to treat mild to moderate disease, while in severe pulmonary hypertension continuous prostacyclin infusion has been shown to improve patients' wellbeing as well as survival. ${ }^{6-8}$ However, prostaglandin $\mathrm{I}_{2}$ (prostacyclin, $\mathrm{PGI}_{2}$ ) has a short half life of less than five minutes in vivo and is therefore quite unstable. It has to be protected from light and needs to be dissolved in a glycine buffer for intravenous administration. ${ }^{9-11}$ Iloprost is a more stable synthetic analogue of $\mathrm{PGI}_{2}{ }^{12}$ It is a comparable pulmonary vasodilator to $\mathrm{PGI}_{2}$ and therefore has potential for the treatment of pulmonary hypertension. ${ }^{13}$ In this prospective study we have compared the effects of iloprost and $\mathrm{PGI}_{2}$ on exercise capacity in patients with severe pulmonary hypertension.

\section{Methods}

The study involved eight patients (four men and four women) diagnosed as having either primary $(n=5)$ or thromboembolic $(n=3)$ pulmonary hypertension, who had had symptoms for an average of 44.6 months and were categorised into New York Heart Association (NYHA) grade III to IV disability. Dyspnoea was the main symptom in all patients, five having chest pain and one syncope. In one patient the onset of symptoms was associated with pregnancy, while in another patient the presentation was Raynaud's syndrome.

The diagnosis of primary pulmonary hypertension was made after excluding other causes of pulmonary hypertension, ${ }^{14}$ and thromboembolic disease was diagnosed by lung scan showing one or more normally ventilated segmental or subsegmental perfusion defects. ${ }^{15}$ Four patients were already taking anticoagulants, five were on calcium channel blockers, and three were on both warfarin and calcium channel blocker treatment (table 1). On entry to the study, all patients stopped taking oral vasodilators and calcium channel blockers, but continued anticoagulants.

The study was approved by the local ethics committee and all patients signed informed consent. Ten patients initially participated, but two were subsequently excluded as they could not comply with the study protocol.

RIGHT HEART CATHETERISATION

All patients had right heart catheterisation. Anticoagulant treatment was stopped before the procedure and written consent was obtained. A triple lumen, flow directed catheter was inserted through the internal jugular vein under local anaesthesia while the patient was lying in a supine position. Mean right atrial pressure, pulmonary arterial pressure, and pulmonary artery wedge pressure values were obtained using electronic integration of the pressure signals, with the mid-axillary line as a zero reference point. Cardiac output was
Accepted for publication 1 October 1997 
Table 1 Characteristics of the patients and anthropometric data

\begin{tabular}{|c|c|c|c|c|c|c|c|c|}
\hline Patient & Age (years) & $\operatorname{Sex}$ & Height $(\mathrm{cm})$ & Weight (kg) & Diagnosis & $\begin{array}{l}\text { NYHA } \\
\text { grade }\end{array}$ & $\begin{array}{l}\text { Duration of } \\
\text { symptoms (months) }\end{array}$ & $\begin{array}{l}\text { Treatment before the } \\
\text { study }\end{array}$ \\
\hline 1 & 48 & M & 181 & 86 & TEPH & IV & 36 & Dilt, Warf \\
\hline 2 & 21 & $\mathrm{~F}$ & 167 & 62 & $\mathrm{PPH}$ & III & 36 & Oxy, Nif, War \\
\hline 3 & 47 & M & 180 & 88 & $\mathrm{PPH}$ & III & 60 & Frum, Dilt, War \\
\hline 4 & 38 & M & 174 & 90 & TEPH & IV & 60 & $\begin{array}{l}\text { Etha, Amil, Nicard, } \\
\text { Pirb }\end{array}$ \\
\hline 5 & 54 & $\mathrm{~F}$ & 158 & 83 & PPH & IV & 20 & Frum, Dilt \\
\hline 6 & 41 & M & 186 & 75 & TEPH & III & 120 & Bum, Amil, War, Pred, \\
\hline 7 & 38 & $\mathrm{~F}$ & 157 & 55 & PPH & III & 13 & Pred \\
\hline 8 & 20 & $\mathrm{~F}$ & 161 & 49 & $\mathrm{PPH}$ & III & 12 & War \\
\hline
\end{tabular}

Amil, amiloride; Bum, bumetanide; Dilt, diltiazem; Etha; ethacrynic acid; Fru, frumil; Nic, nicardipine; Pirb, pirbuterol; War, warfarin; PPH, primary pulmonary hypertension; Pred, prednisolone; TEPH, thromboembolic pulmonary hypertension.

measured by thermodilution technique using a bedside cardiac output computer (American Edwards Laboratory, Santa Ana, California, USA). Pulmonary vascular resistance (mean pulmonary artery pressure minus pulmonary artery wedge pressure divided by cardiac output) was calculated in Wood units (wu). Cardiac rhythm was monitored using continuous electrocardiography, and arterial pressure was monitored from a radial artery cannula. Blood samples were obtained from pulmonary and radial arteries for gas tension analysis.

ACUTE VASODILATOR TRIAL

After obtaining baseline measurements, an intravenous $\mathrm{PGI}_{2}$ infusion was started at an initial dose of approximately $2 \mathrm{ng} / \mathrm{kg} / \mathrm{min}$, which was then increased stepwise after five to 15 minutes by 1 to $2 \mathrm{ng} / \mathrm{kg} / \mathrm{min}$. Epoprostenol (prostacyclin, $\mathrm{PGI}_{2}$ ) was supplied by Wellcome Foundation (Beckenham, Kent, UK) as a sodium salt which was dissolved in an accompanying glycine buffer before diluting it in normal saline. All the haemodynamic measurements and blood samples were obtained before increasing the dose. This acute vasodilator study was continued until there was a $20 \%$ reduction in pulmonary vascular resistance or a fall of systolic systemic blood pressure below $100 \mathrm{~mm} \mathrm{Hg}$. As it takes five minutes for $\mathrm{PGI}_{2}$ to be inactivated, ${ }^{16}$ twenty minutes were allowed after stopping $\mathrm{PGI}_{2}$ before starting the intravenous infusion of iloprost. The order was chosen because iloprost has a half life of over 13 minutes. ${ }^{13}$ Iloprost (supplied by Schering Healthcare, Burgess Hill, Sussex, UK) was available in $1 \mathrm{ml}$ ampoules containing $100 \mu \mathrm{g}$ of the drug in sterile physiological saline with the addition of Tris buffer $(\mathrm{pH} \mathrm{8.3)}$ and ethanol $(1 \%)$. This was diluted in normal saline to prepare the intravenous infusion. Iloprost infusion was started at approximately 1 to $2 \mathrm{ng} / \mathrm{kg} / \mathrm{min}$ and increased in a stepwise fashion according to the protocol as for $\mathrm{PGI}_{2}$. Haemodynamic measurements and blood samples were taken every five to 15 minutes before increasing the dose.

\section{LONG TERM TREATMENT}

After the right heart catheterisation, patients were allocated for phase I of the study infusion (either $\mathrm{PGI}_{2}$ or iloprost), given through an indwelling central line. The syringe containing the solution was driven by an electric pump which was carried by the patients in a small shoulder holster and did not restrict their mobility. The pump was protected from light, and the patients were taught the aseptic technique of preparing the solution, as well as the storage, administration, and maintenance of the infusion, which they were able to do independently at home. At the end of phase I, patients crossed over to phase II (the alternative treatment). The duration of $\mathrm{PGI}_{2}$ and iloprost infusion varied for individual patients (range 4 to 19 weeks for $\mathrm{PGI}_{2}$ and 3.5 to 11 weeks for iloprost); on average both $\mathrm{PGI}_{2}$ and iloprost were given for seven weeks. It was intended to keep the duration of both phase I and phase II to four weeks but this could not be achieved. (The variation in the treatment duration occurred because patients were referred from other centres and at times they had to travel long distances; therefore follow up periods were kept flexible.) Exercise tolerance was measured at baseline while patients were on their previous treatments, and then at the end of each phase using a monitored 12 minute

Table 2 Baseline right heart catheter data for patients and results of acute infusion of either prostacyclin or iloprost

\begin{tabular}{|c|c|c|c|c|c|c|c|c|c|c|c|c|c|c|c|c|c|c|}
\hline \multirow[b]{2}{*}{ Patient } & \multirow[b]{2}{*}{ Diagnosis } & \multicolumn{5}{|l|}{ Baseline } & \multicolumn{6}{|c|}{ Epoprostenol } & \multicolumn{6}{|l|}{ Iloprost } \\
\hline & & $m R A P$ & $m P A P$ & $C I$ & $P V R$ & $\mathrm{SvO}_{2}$ & $m R A P$ & $m P A P$ & $C I$ & $P V R$ & $\mathrm{SvO} \mathrm{O}_{2}$ & Dose & $m R A P$ & $m P A P$ & $C I$ & $P V R$ & $\mathrm{SvO}_{2}$ & Dose \\
\hline 1 & TEPH & 15 & 60 & 1.7 & 12.8 & 46 & 14 & 58 & 2.1 & 10.2 & 60 & 6.2 & - & - & - & - & - & - \\
\hline 2 & PPH & 5 & 69 & 1.6 & 16.6 & 57 & 5 & 68 & 2.0 & 13.5 & 65 & 6.4 & 4 & 64 & 2.1 & 14.2 & 66 & 9.7 \\
\hline 3 & $\mathrm{PPH}$ & 11 & 55 & 2 & 10.8 & 66 & 9 & 44 & 2.3 & 8.0 & 76 & 6.1 & 9 & 44 & 2.4 & 8.2 & 72 & 3.0 \\
\hline 4 & TEPH & 6 & 66 & 1.7 & 15.5 & 55 & 5 & 58 & 2.4 & 9.1 & 57 & 4.4 & 5 & 52 & 2.8 & 7.1 & 58 & 6.7 \\
\hline 5 & PPH & 18 & 68 & 1.9 & - & 52 & 13 & 49 & 2.7 & - & 71 & 6.4 & 14 & 53 & 2.7 & - & 64 & 4.8 \\
\hline 6 & TEPH & 17 & 67 & 1.2 & - & 58 & 13 & - & 1.6 & - & 65 & 5.3 & - & - & - & - & - & - \\
\hline 7 & $\mathrm{PPH}$ & 4 & 70 & 1.5 & 25.2 & 65 & 7 & 74 & 1.7 & - & 64 & 7.3 & 8 & 79 & 1.9 & - & 73 & 10.9 \\
\hline 8 & PPH & 3 & 84 & 2.4 & 21.1 & 74 & 1 & 77 & 3.4 & 14.2 & 72 & 8.2 & - & 69 & 3.7 & 11.7 & - & 8.2 \\
\hline Mean & & 9.9 & 67.4 & 1.7 & 17.0 & 59.1 & 8.4 & $61.1^{\star}$ & $2.3^{\star}$ & $11.0^{\star}$ & $66.2^{\star}$ & 6.3 & 6.7 & $59.7^{\star}$ & $2.6^{\star}$ & 10.3 & $66.6^{\star}$ & 7.2 \\
\hline SEM & & $(2.2)$ & $(3.0)$ & $(0.1)$ & $(2.2)$ & $(3.1)$ & $(1.7)$ & $(4.7)$ & $(0.2)$ & $(1.2)$ & $(2.2)$ & $(0.4)$ & $(2.0)$ & $(5.1)$ & $(0.2)$ & $(1.6)$ & $(2.7)$ & (1.3) \\
\hline
\end{tabular}

${ }^{\star} \mathrm{p}<0.05$.

$\mathrm{CI}$, cardiac index $\left(1 / \mathrm{min} / \mathrm{m}^{2}\right)$; mRAP, mean right atrial pressure $(\mathrm{mm} \mathrm{Hg}) ; \mathrm{mPAP}$, mean pulmonary artery pressure (mm Hg); PVR, pulmonary vascular resistance; $\mathrm{SvO}_{2}$, mixed venous oxygen saturation (\%); $\mathrm{PPH}$, primary pulmonary hypertension; TEPH, thromboembolic pulmonary hypertension. 
Table 3 Twelve minute walk data at baseline

\begin{tabular}{lllccl}
\hline Patient & Diagnosis & Distance $(m)$ & Rest $(s)$ & $\Delta \mathrm{SaO}_{2}(\%)$ & $\Delta \mathrm{HR}(\%)$ \\
\hline 1 & TEPH & 280 & 0 & 3.1 & 31.3 \\
2 & PPH & 560 & 85 & 3.2 & 63.7 \\
3 & PPH & 570 & 165 & 16.9 & 25.6 \\
4 & TEPH & 180 & 420 & 4.2 & 19.5 \\
5 & PPH & 120 & 360 & 31.8 & 14.9 \\
6 & TEPH & 380 & 505 & 7.7 & 49.5 \\
7 & PPH & 720 & 0 & - & 56.4 \\
8 & PPH & 450 & 0 & 49.4 & 38.8 \\
Mean & & 407.5 & 192 & 16.6 & 37.5 \\
(SEM) & & $(73)$ & $(73)$ & $(6.7)$ & $(6.3)$ \\
\hline
\end{tabular}

$\Delta \mathrm{HR}(\%)$, percentage increase in heart rate; $\Delta \mathrm{SaO}_{2}(\%)$, percentage drop in oxygen saturation; $\mathrm{PPH}$, primary pulmonary hypertension; TEPH, thromboembolic pulmonary hypertension.

Table 4 Twelve minute walk data on epoprostenol (PGI $)$

\begin{tabular}{lllclllc}
\hline Patient & Diagnosis & Distance $(m)$ & Rest $(s)$ & $\begin{array}{l}\Delta \mathrm{SaO}_{2} \\
(\%)\end{array}$ & $\begin{array}{l}\Delta \mathrm{HR}(\%) \\
\text { (weeks) }\end{array}$ & $\begin{array}{l}\text { Duration } \\
\text { (wose } \mathrm{PGI}_{2} \\
\text { (ng/kg/min) }\end{array}$ \\
\hline 1 & TEPH & 360 & 0 & - & - & 19 & 5.5 \\
2 & PPH & 620 & 0 & 11.1 & 41.3 & 7 & 20 \\
3 & PPH & 680 & 0 & - & - & 4.5 & 6.3 \\
4 & TEPH & 520 & 0 & 4.1 & 28.6 & 5 & 15.8 \\
5 & PPH & 490 & 125 & - & - & 4 & 4 \\
6 & TEPH & 700 & 0 & 4.3 & 42.5 & 4 & 3.8 \\
7 & PPH & 760 & 0 & 3.1 & 26.8 & 5 & 6.9 \\
8 & PPH & 600 & 0 & - & 35.8 & 7.5 & 7.3 \\
Mean & & $591^{\star \star}$ & $16^{\star}$ & 6 & 35 & 7 & 8.7 \\
$($ SEM) & & $(46)$ & $(16)$ & $(1.8)$ & $(3.2)$ & $(1.8)$ & $(2.2)$ \\
\hline
\end{tabular}

${ }^{\star} \mathrm{p}<0.05,{ }^{\star \star} \mathrm{p}<0.01$ compared to baseline.

$\Delta \mathrm{HR}(\%)$, percentage increase in heart rate; $\Delta \mathrm{SaO}_{2}(\%)$, percentage drop in oxygen saturation; $\mathrm{PPH}$, primary pulmonary hypertension; TEPH, thromboembolic pulmonary hypertension.

walk. ${ }^{17}$ During the 12 minute walk, arterial oxygen saturation and heart rate were monitored. Duration of rest periods during the test was also recorded.

Of the two patients who were excluded from the initial cohort, one received only iloprost and was not willing to cross over to $\mathrm{PGI}_{2}$ in phase II; the second patient was excluded from the analysis because his baseline exercise data were not available.

\section{STATISTICAL ANALYSIS}

Distance covered during the 12 minute walk was recorded in metres and the rest period was recorded in seconds. Heart rate (beats/min) was noted at rest and then at each minute interval. The difference between resting and maximum heart rate was calculated in percentage rise in heart rate $(\Delta \mathrm{HR} \%)$. Degree of oxygen desaturation was calculated as percentage fall in oxygen saturation $\left(\Delta \mathrm{SaO}_{2} \%\right)$, taking into account oxygen saturation at rest and minimum saturation during exercise. During right heart catheterisation mean right atrial and pulmonary artery pressures were recorded

Table 5 Twelve minute walk data on iloprost

\begin{tabular}{|c|c|c|c|c|c|c|c|}
\hline Patient & Diagnosis & $\begin{array}{l}\text { Distance } \\
(m)\end{array}$ & Rest (s) & $\begin{array}{l}\underset{\mathrm{Sa} a \mathrm{O}_{2}}{(\%)}\end{array}$ & $\Delta H R(\%)$ & $\begin{array}{l}\text { Duration } \\
\text { (weeks) }\end{array}$ & $\begin{array}{l}\text { Dose PGI } \\
\text { (ng/kg/min) }\end{array}$ \\
\hline 1 & TEPH & 420 & 0 & 0 & 0 & 3.5 & 2.1 \\
\hline 2 & $\mathrm{PPH}$ & 740 & 0 & 2 & 50 & 6 & 2.7 \\
\hline 3 & $\mathrm{PPH}$ & 880 & 0 & - & - & 8 & 1.0 \\
\hline 4 & TEPH & 340 & 260 & 4.1 & 23.7 & 5 & 1.7 \\
\hline 5 & PPH & 580 & 55 & 13.5 & 15.3 & 7 & 0.7 \\
\hline 6 & TEPH & 580 & 150 & 6 & 20.8 & 11 & 1.6 \\
\hline 7 & PPH & 640 & 0 & 1 & 27.1 & 8 & 3.4 \\
\hline 8 & PPH & 640 & 0 & 46.9 & 32 & 7.5 & 3.9 \\
\hline \multirow{2}{*}{\multicolumn{2}{|c|}{$\begin{array}{l}\text { Mean } \\
\text { (SEM) }\end{array}$}} & $602.5 \dagger$ & $58 \dagger$ & $10.5^{\star}$ & $24.1^{\star}$ & 7 & $2.1 \ddagger$ \\
\hline & & (60) & (34) & (6.3) & (5.8) & $(0.8)$ & $(0.4)$ \\
\hline
\end{tabular}

${ }^{\star} \mathrm{p}<0.005, \mathrm{tp}<0.001$ comparison with baseline; $\neq \mathrm{p}<0.05$ comparison with $\mathrm{PGI}_{2}$ and iloprost dose.

$\Delta \mathrm{HR}(\%)$, percentage increase in heart rate; $\Delta \mathrm{SaO}_{2}(\%)$, percentage drop in oxygen saturation; $\mathrm{PPH}$, primary pulmonary hypertension; TEPH, thromboembolic pulmonary hypertension. in $\mathrm{mm} \mathrm{Hg}$; cardiac output in $1 / \mathrm{min}$ and cardiac index in $1 / \mathrm{min} / \mathrm{m}^{2}$ of body surface area. Comparisons of exercise and haemodynamic data on $\mathrm{PGI}_{2}$ and iloprost with respect to baseline were made using the paired Wilcoxon test. It was assumed that there was no carry over effect from phase I to phase II and the comparisons were based on the tests of the treatment results versus the baseline. Results are shown as mean with a standard error. A p value of less than 0.05 was regarded as statistically significant.

\section{Results}

ACUTE RESPONSE TO TREATMENT

Baseline measurements during right heart catheterisation indicated the severity of pulmonary hypertension (table 2). After a vasodilator challenge, there was no significant change in right atrial pressure, either with $\mathrm{PGI}_{2}$ or iloprost: 9.9 (2.2) at baseline $v 8.4$ (1.7) $\mathrm{mm} \mathrm{Hg}$ with $\mathrm{PGI}_{2}$ and 6.7 (2.0) $\mathrm{mm} \mathrm{Hg}$ with iloprost (table 2 ). The mean pulmonary artery pressure fell from $67.4(3.0)$ to $61.1(4.7) \mathrm{mm} \mathrm{Hg}$ with $\mathrm{PGI}_{2}(\mathrm{p}=0.04)$ and to 59.7 (5.1) $\mathrm{mm} \mathrm{Hg}$ with iloprost $(p<0.05)$, while cardiac index improved both with $\mathrm{PGI}_{2}$ and iloprost (1.75 $(0.1) \mathrm{l} / \mathrm{min} / \mathrm{m}^{2}$ at baseline to $2.3(0.2)$ $1 / \mathrm{min} / \mathrm{m}^{2}$ with $\mathrm{PGI}_{2}(\mathrm{p}=0.004)$ and $2.6(0.2)$ $1 / \mathrm{min} / \mathrm{m}^{2}$ with iloprost $\left.(\mathrm{p}=0.02)\right)$. The pulmonary vascular resistance was not measured in some patients, because of difficulties in measuring either the pulmonary artery wedge pressure or the cardiac output. Where it was measured, there was a fall from baseline with both $\mathrm{PGI}_{2}$ and iloprost: 17 (2.2) wu at baseline $(\mathrm{n}=6)$ to $11(1.2)$ wu with $\mathrm{PGI}_{2} \quad(\mathrm{n}=5$, $\mathrm{p}=0.03$ ), and to 10.3 (1.6) wu with iloprost $(\mathrm{n}=4)$. Mixed systemic venous oxygen saturation $\left(\mathrm{SvO}_{2}\right)$ improved with both drugs: $59.1(3.1) \%$ at baseline to $66.25(2.2) \%$ with PGI $_{2}(\mathrm{p}<0.05)$ and to $66.6(2.7) \%$ with iloprost $(p=0.03)$ (table 2).

\section{LONG TERM TREATMENT}

All patients were able to perform a 12 minute walk test to assess exercise tolerance at baseline. There was an improvement in exercise tolerance, as judged by the distance covered and the duration of rest required during the walk test: 407.5 (73) $\mathrm{m}$ at baseline increasing to $591(46) \mathrm{m}$ with $\mathrm{PGI}_{2}$ $(\mathrm{p}=0.004) \quad$ (tables 3 and 4$)$, and to 602.5 (60) $\mathrm{m}$ with iloprost (tables 3 and 5) $(p=0.008)$. Rest periods required by the patients were less while on $\mathrm{PGI}_{2}$ or iloprost: 192 (73) at baseline $v 16$ (16) seconds on $\mathrm{PGI}_{2}$ $(\mathrm{p}=0.02)$, and 58 (34) seconds on iloprost $(\mathrm{p}=0.008)$. There was a trend towards less oxygen desaturation $\left(\Delta \mathrm{SaO}_{2} \%\right)$ during exercise while on $\mathrm{PGI}_{2}$ and iloprost compared with baseline; however, data availability was restricted because of the low peripheral perfusion in some patients, which caused difficulty in measuring transcutaneous oxygen saturation: $16.6(6.7) \% \mathrm{O}_{2}$ desaturation at baseline $(\mathrm{n}=7)$ v 6(1.8)\% with $\mathrm{PGI}_{2}(\mathrm{n}=4)$ and $10.5(6.3) \%$ with iloprost $(n=7)(p=0.02)$. The $\Delta H R \%$ during exercise was $37.5(6.3) \%$ at baseline 
( $\mathrm{n}=8$ ) compared with $35(3.2) \%$ while on $\mathrm{PGI}_{2}(\mathrm{n}=5)$, and $24.1(5.8) \%$ while on iloprost $(\mathrm{n}=7)(\mathrm{p}=0.04)($ tables 3,4 , and 5).

\section{Discussion}

In this study we have shown the effect of a $\mathrm{PGI}_{2}$ analogue, iloprost, on exercise tolerance of patients with pulmonary hypertension. While on iloprost, the improvement in the distance covered during the 12 minute walk was more than $200 \mathrm{~m}$. This, in conjunction with the reduced rest period required during the exercise test, suggests that these patients would have experienced enhancement in their daily activities. The number of patients studied is small but provides evidence that iloprost may improve the exercise capacity of patients with severe pulmonary hypertension. Similar results have been reported in patients with systemic sclerosis and pulmonary hypertension. ${ }^{18}$

Iloprost has a similar molecular structure to $\mathrm{PGI}_{2}$ and works through $\mathrm{PGI}_{2}$ receptors present on the vascular endothelial cells. ${ }^{19} 20$ Similar in function to $\mathrm{PGI}_{2}$, it is a potent vasodilator of the pulmonary vascular bed ${ }^{13}$ and also inhibits platelet aggregation. ${ }^{18}$ It is a relatively more stable compound than $\mathrm{PGI}_{2} \cdot{ }^{12}$ It can be dissolved in isotonic solution, does not have to be protected from light, and can be stored at room temperature.

The haemodynamics were not uniform in all patients. Right atrial pressure, cardiac index, and mixed $\mathrm{SvO}_{2}$ have prognostic value and varied in the subjects studied. In five patients the mean right atrial pressure was below $10 \mathrm{~mm} \mathrm{Hg}$, while in the other three it was in excess of $10 \mathrm{~mm} \mathrm{Hg}$. In patients 3 and 8, the cardiac index was 2 and $2.4 \mathrm{l} / \mathrm{min} / \mathrm{m}^{2}$ respectively, while in six other patients it was below $21 / \mathrm{min} / \mathrm{m}^{2}$, suggesting marked right ventricular dysfunction. ${ }^{2}$ However, the majority of patients had an $\mathrm{SvO}_{2} \%$ of less than $63 \%$, suggesting severe disease, ${ }^{1}$ and all were severely disabled, being categorised into NYHA grade III-IV, which is also associated with a poor prognosis.?

It may also be argued that there was no washout period between $\mathrm{PGI}_{2}$ and iloprost, allowing carry over effects of the first treatment. However $\mathrm{PGI}_{2}$ has a short half life of minutes $^{16}$ and it is unlikely that vasodilator activity would have lasted for any significant period on changing from phase I to phase II of the study. There was an ethical reason for not having a washout with a placebo between phase I and II: as the subjects had a potentially fatal disease, there was a risk of causing a rapid haemodynamic and symptomatic deterioration on stopping potent vasodilator treatment.

Five patients had $\mathrm{PGI}_{2}$ and three had iloprost in phase I. After crossover to the alternative drug there was no worsening of symptoms and the improvement of exercise tolerance in each patient was generally maintained. In two patients there was a slight decline in the 12 minute walk distance on switching from $\mathrm{PGI}_{2}$ to iloprost, and two patients decreased their walking distance slightly on changing from iloprost to $\mathrm{PGI}_{2}$. However, the duration of rest required during the 12 minute walk did not increase for any of these patients. Notably, all five patients who were on calcium channel blockers at baseline improved their exercise tolerance while on iloprost.

As this is a short term study involving eight patients, it may be necessary to conduct a long term survival study to evaluate the therapeutic role of iloprost fully. However, these early data suggest that the prostacyclin analogue iloprost may be an effective long term treatment for severe pulmonary hypertension, and it is generally well tolerated - headaches, diarrhoea, and abdominal pain may occur initially but usually settle after 24 to 48 hours. There is some evidence that this analogue of $\mathrm{PGI}_{2}$ may be a little more stable, with an in vivo half life of approximately 13 minutes, ${ }^{12}$ compared with five minutes for $\mathrm{PGI}_{2}$. At present it has to be given as a continuous intravenous infusion through a central line, which may occasionally create problems such as infection, blockage, and displacement of the line. Finally iloprost is approximately twice as strong a vasodilator as $\mathrm{PGI}_{2}$ - only half the dose is required to produce the same long term effects. This might reduce the already high cost of these drugs.

\section{CONCLUSION}

We have shown that the synthetic prostacyclin analogue iloprost may improve the exercise tolerance of patients with severe pulmonary hypertension. Its effect on long term survival in pulmonary hypertension is, however, not known. Its therapeutic efficacy would probably need to be further evaluated in a larger survival study.

We are grateful to Schering Health Care Ltd for providing us with the supply of iloprost, as well as for the patients' travel grants.

1 Fuster V, Steele PM, Edwards WD, et al. Primary pulmonary hypertension: natural history and importance of pulmonary hypertension: natural history

2 D'Alonzo GE, Barst RJ, Ayres SM, et al. Survival in patients with primary pulmonary hypertension. Ann Intern Med with primary pul.

3 Rich S, Dantzker DR, Ayres SM, et al. Primary pulmonary hypertension. A national prospective study. Ann Intern Med 1987;107:216-23.

4 Rich S, Brundage BH. High dose calcium channel blocking therapy for primary pulmonary hypertension: evidence for long-term reduction in pulmonary arterial pressure and regression of right ventricular hypertrophy. Circulation 1987;76:135-41.

5 Rich S, Kaufmann E, Levy P. The effect of high doses of calcium channel blockers on survival in primary pulmonary hypertension. $N$ Engl F Med 1992;327:76-81.

6 Jones DK, Higenbottam TW, Wallwork J. Treatment of primary pulmonary hypertension with intravenous epoprostenol (prostacyclin). Br Heart $\mathcal{F} 1987 ; 57: 270-8$.

7 Higenbottam TW, Spiegelhalter D, Scott J, et al. Prostacyclin (epoprostenol) and heart-lung transplantation as treatments of severe pulmonary hypertension. Br Heart $\mathcal{~} 1993$; ments of se

8 Butt AY, Cremona G, Sharples L, et al. Continuous infusion of prostacyclin $\left(\mathrm{PGI}_{2}\right)$ improves survival in severe pulmonary hypertension [abstract]. I Am Coll Cardiol 1995; (suppl):221A

9 Barst R, Rubin L, Long W, et al. A comparison of continuous intravenous epoprostenol (prostacyclin) with conventional therapy for primary pulmonary hypertension. $N \mathrm{Engl}$ f Med 1996;334:296-301.

10 Higenbottam T. The place of prostacyclin in the clinical management of primary pulmonary hypertension. Am Rev Respir Dis 1987;136:782-5.

11 Barst RJ, Rubin LJ, McGoon MD, et al. Survival in primary pulmonary hypertension with long-term continuous intravenous prostacyclin. Ann Intern Med 1994;121:409-15. 2 Kaukinen S, Ylitalo P, Pessi T, Vapaatalo H. Hemodynamic effects of iloprost, a prostacyclin analog. Clin Pharmacol
Ther 1984;36:464-9.

3 Scott JP, Higenbottam TW, Wallwork J. The acute effect of the synthetic prostacyclin analogue iloprost in primary pul-
monary hypertension. Br f Clin Pharmacol 1990;6:231-4. 
14 Butt AY, Higenbottam TW. Primary pulmonary hypertension In: Jackson G, ed. Difficult concepts in cardiology. London: Marin Dunitz, 1994:215-43.

15 Hull RD, Raskob GE, Heish J. The diagnosis of a clinically suspected pulmonary embolism. Practical approaches. Chest 1986;89(suppl):417-25.

16 Haslam RJ, McClenaghan MD. Measurement of circulating prostaglandin. Nature 1981;292:364-7.

17 McGavin CR, Gupta SP, McHardy GJR. Twelve minute walking test for assessing disability in chronic bronchitis. BMF 1976;i:822-3.
18 De Mata LJ, Gomez-Sanchez MA, Aranzana M, et al. Longterm iloprost infusion therapy for severe pulmonary hypertension in patients with connective tissue disease. Arthritis Rheum 1994;37:1528-33.

19 Schror K, Darius H, Matzky R, et al. The anti platelet and cardiovascular actions of a new carbacyclin derivative (ZK36374) - equipotent to $\mathrm{PGI}_{2}$ in vitro. Arch Pharmacol 1981;316:252-5.

20 Bugiardini R, Galvani M, Ferrini D, et al. Effects of iloprost, a stable prostacyclin analog, on exercise capacity and platelet aggregation in stable angina pectoris. Am $\mathcal{F}$ Cardiol 1986;58:453-9. 